\title{
The impact of a sense of belonging on lethargy and career maturity
}

\author{
Fumihiro Omasu*, Yuiko Takahashi \\ Department of School Health, Graduate School of Education, Kumamoto University, Kumamoto, Japan; \\ *Corresponding Author: fomasu@educ.kumamoto-u.ac.jp
}

Received 11 July 2013; revised 8 August 2013; accepted 15 August 2013

Copyright (C) 2013 Fumihiro Omasu, Yuiko Takahashi. This is an open access article distributed under the Creative Commons Attribution License, which permits unrestricted use, distribution, and reproduction in any medium, provided the original work is properly cited.

\section{ABSTRACT}

In this study, the authors treated a combination of psychological apathy and decreased motivation as a tendency to lethargy, and implemented a survey into the tendency to lethargy demonstrated by students, in order to study the impact of a sense of belonging in the four relationships between the student and the people considered most likely to be interacted with during university life-those with family, friends at university, friends outside university and boyfriend/girlfriend. In addition, the authors implemented a survey and study that included additional categories relating to career maturity. The study was performed on $\mathbf{2 5 0}$ university students, using an anonymous questionnaire that graded responses using criteria to measure a sense of belonging, psychological apathy characteristics, areas of decreased motivation, and career maturity. The subjects were classified by the school year to which they belonged, their gender, and whether or not they had a boyfriend/girlfriend, and consideration was given to the relationship between psychological apathy, decreased motivation, career maturity and a sense of belonging. In terms of gender difference in regard to each of the criteria, partially, the study indicated that male students score significantly higher than female students in terms of a sense of belonging, females score significantly higher than males for decreased motivation in regard to classes, and males score significantly higher than females in relation to career maturity. No significant difference in scores was noted between males and females in relation to psychological apathy. The impact of a sense of belonging on psychological apathy, decreased motivation and career moti- vation was seen in the fact that across all categories, those students with a good relationship with friends at university had a suppressed level of decreased motivation in regard to university by the portions given in this document.

Keywords: Sense of Belonging; Psychological Apathy; Decreased Motivation; Tendency to Lethargy; Career Maturity

\section{INTRODUCTION}

School maladaptation caused by lethargy, decreased motivation and disinterest among students has long been seen as a problem. According to a study of university students who either put their studies on hold or left university, or who were repeating a year of school [1], a large number of passive reasons were given for putting on hold or leaving studies. These passive reasons include a reduction or loss of motivation in regard to study, insufficient credits, and student apathy, all of which make up a significant proportion of responses. There is no need to debate the importance of support on a mental level. Furthermore, among students with experience of repeating a year, the most common reason given for the repeated year was "I cannot find the motivation to learn", while the most common reason given by students giving reasons related to their poor health was "Irregular lifestyle" followed by "Mental concerns and anxieties", demonstrating the need for mental support among university students.

Currently, absenteeism is the major problem with school adaptation in junior high schools throughout Japan. It has been indicated that a sense of belonging in each type of relationship has a positive impact on promoting mental health and school adaptation among junior high school students, and it is clear that a sense of belonging has a significant impact on absenteeism [2]. 
For university students, results [2,3] have been published showing that a sense of belonging has no relationship to school adaptation, so that while the central problem of school adaptation for junior high school students is absenteeism, indicating an overall withdrawal from school, the central problem of school adaptation for university students tends to be student apathy, resulting in partial withdrawal from school, and as such analyzing these in the same study has been stated as insufficient. As stated above, the fact that the central problem of school adaptation for university students is student apathy can be ascribed to the particular situation in which Japan finds itself. The current system by which Japanese students move from school to university is increasingly dealing with younger students, and becoming more institutionalized, and university students pass through this particular system in order to enter university. As a result, as pointed out by Shimoyama [4], the situation in which many Japanese university students find themselves in their late adolescence is a unique moratorium, which is qualitatively different to the classical situation of late adolescence.

In this study, the authors implemented a survey into the tendency to lethargy demonstrated by university students, in order to study the impact of a sense of belonging in the four relationships between the student and the people considered most likely to be interacted with during university life ) - those with family, friends at university, friends outside university and boyfriend/girlfriend. In addition, it is believed that learning activities at university equate to behavior that targets final career decisions. For this reason, the authors assumed that there must be a correlation between motivation in regard to university life and attitude to career decisions, and therefore added categories relating to career maturity, with the objective of finding directions related to support for students who demonstrate lethargy.

\section{METHODS}

The survey covered 250 university students (118 male and 132 female). The average age of subjects was $20.4 \pm$ 1.4 years (mean \pm standard deviation). The survey was implemented on all students during class hours, using an anonymous questionnaire. In addition, it was distributed and collected either directly or through acquaintances. The criteria used for a sense of belonging were devised by Ishimoto [2,3]. An overall sense of belonging comprised two factors, the "factor contributing to a sense of intrinsic comfort", which gives the sense that one can be oneself, and the "factor contributing to a sense of one's own usefulness", which gives the sense that one is needed. The criteria for psychological apathy characteristics and areas of decreased motivation were taken from Shimoyama [5]. The criteria for areas of decreased mo- tivation covered the three factors of "decreased motivation in regard to academic life", "decreased motivation in regard to classes" and "decreased motivation in regard to university". Career maturity was examined using the criteria for career maturity [6] defined by the Japan Careers Guidance Association (Nihon Shinro Shido Kyokai). This involved three criteria: "attitude of self-realization", which expresses an awareness of aiming to realize oneself via employment, "career planning", which expresses the extent to which the student is currently engaged in practical activities with a view to future employment situations, and "career decisions", which express the strength of decision-making in regard to the type of employment hoped for in the future. Responses were selected from five levels ranging from "Entirely inapplicable (1 mark)" through to "Extremely applicable (5 marks)". The analysis was implemented based on classification according to gender, and whether or not the subject had a boyfriend/girlfriend. The gender difference for each category was calculated as an average value for each criteria, and the difference between average values for males and females was compared using the MannWhitney U-test, before its relationship to psychological apathy, decreased motivation, career maturity and a sense of belonging were subjected to multiple regression analysis, with psychological apathy, decreased motivation and career maturity taken as objective variables, and a sense of belonging as the explanatory variable.

\section{RESULTS}

\subsection{Breakdown of Subjects}

A total of 250 subjects were categorized according to school year, gender and whether or not they had a girlfriend/boyfriend (Table 1).

\subsection{Gender Difference for Each Criterion}

Table 2 shows the average values and standard deviation, as well as the results of comparison of average values between males and females, for a sense of belonging in regard to relationships with family, friends at university, friends outside university and boyfriend/girlfriend; psychological apathy, decreased motivation in regard to academic life, decreased motivation in regard to classes,

Table 1. Breakdown of subjects (no. of people).

\begin{tabular}{|c|c|c|c|c|}
\hline \multicolumn{2}{|c|}{ Males } & \multicolumn{2}{|c|}{ Females } & \multirow[b]{2}{*}{ Total } \\
\hline $\begin{array}{l}\text { Has } \\
\text { boyfriend/ } \\
\text { girlfriend }\end{array}$ & $\begin{array}{l}\text { Does not have } \\
\text { boyfriend/ } \\
\text { girlfriend }\end{array}$ & $\begin{array}{l}\text { Has } \\
\text { boyfriend/ } \\
\text { girlfriend }\end{array}$ & $\begin{array}{l}\text { Does not have } \\
\text { boyfriend/ } \\
\text { girlfriend }\end{array}$ & \\
\hline \multirow[t]{2}{*}{42} & 76 & 66 & 66 & \multirow{2}{*}{250} \\
\hline & 18 & & 132 & \\
\hline
\end{tabular}


Table 2. Average values, SD and comparison between males and females for each (a) criteria among the group who had a boyfriend/girlfriend; (b) criterion among the group without a boyfriend/girlfriend.

(a)

\begin{tabular}{|c|c|c|c|c|c|}
\hline & & $\begin{array}{c}\text { Overall (SD) } \\
\mathrm{n}=108\end{array}$ & $\begin{array}{c}\text { Males (SD) } \\
\mathrm{n}=42\end{array}$ & $\begin{array}{c}\text { Females (SD) } \\
n=66\end{array}$ & $\mathrm{M} / \mathrm{F}$ comparison \\
\hline \multirow{3}{*}{ Family } & A sense of belonging & $3.94(0.10)$ & $3.65(1.05)$ & $4.13(0.91)$ & $\mathrm{P}<0.01$ \\
\hline & A sense of one's own usefulness & $3.89(0.99)$ & $3.51(1.05)$ & $4.13(0.88)$ & $\mathrm{P}<0.01$ \\
\hline & A sense of intrinsic comfort & $4.16(0.98)$ & $4.19(0.86)$ & $4.14(1.05)$ & N.S. \\
\hline \multirow{3}{*}{ Friends at university } & A sense of belonging & $3.70(0.86)$ & $3.62(0.92)$ & $3.74(0.81)$ & N.S. \\
\hline & A sense of one's own usefulness & $3.66(0.84)$ & $3.56(0.89)$ & $3.73(0.80)$ & N.S. \\
\hline & A sense of intrinsic comfort & $3.83(0.90)$ & $3.88(0.99)$ & $3.80(0.85)$ & N.S. \\
\hline \multirow{3}{*}{ Friends outside university } & A sense of belonging & $3.90(0.82)$ & $3.92(0.88)$ & $3.89(0.78)$ & N.S. \\
\hline & A sense of one's own usefulness & $3.90(0.79)$ & $3.88(0.87)$ & $3.91(0.75)$ & N.S. \\
\hline & A sense of intrinsic comfort & $3.94(0.92)$ & $4.10(0.93)$ & $3.83(0.90)$ & N.S. \\
\hline \multirow{3}{*}{ Boyfriend/girlfriend } & A sense of belonging & $4.19(0.95)$ & $4.15(0.89)$ & $4.22(0.99)$ & N.S. \\
\hline & A sense of one's own usefulness & $4.16(0.97)$ & $4.14(0.89)$ & $4.17(1.03)$ & N.S. \\
\hline & A sense of intrinsic comfort & $4.32(0.83)$ & $4.19(0.89)$ & $4.41(0.78)$ & N.S. \\
\hline \multicolumn{2}{|l|}{ Psychological apathy } & $2.91(1.18)$ & $2.93(1.21)$ & $2.89(1.16)$ & N.S. \\
\hline \multicolumn{2}{|c|}{ Decreased motivation in regard to classes } & $3.00(1.24)$ & $3.18(1.24)$ & $2.88(1.22)$ & N.S. \\
\hline \multicolumn{2}{|c|}{ Decreased motivation in regard to academic life } & $3.27(1.09)$ & $3.34(1.16)$ & $3.23(1.05)$ & N.S. \\
\hline \multicolumn{2}{|c|}{ Decreased motivation in regard to university } & $2.42(1.07)$ & $2.34(1.10)$ & $2.47(1.03)$ & N.S. \\
\hline \multicolumn{2}{|l|}{ Overall motivation } & $2.90(1.21)$ & $2.95(1.25)$ & $2.86(1.14)$ & N.S. \\
\hline \multicolumn{2}{|l|}{ Self-realization } & $4.63(0.64)$ & $4.64(0.69)$ & $4.62(0.60)$ & N.S. \\
\hline \multicolumn{2}{|l|}{ Career planning } & $3.56(0.99)$ & $3.48(1.06)$ & $3.62(0.94)$ & N.S. \\
\hline \multicolumn{2}{|l|}{ Career decisions } & $4.06(1.02)$ & $3.83(1.17)$ & $4.21(0.89)$ & N.S. \\
\hline \multicolumn{2}{|l|}{ Overall career } & $4.09(0.99)$ & $3.98(1.10)$ & $4.15(0.92)$ & N.S. \\
\hline
\end{tabular}

(b)

\begin{tabular}{|c|c|c|c|c|c|}
\hline & & $\begin{array}{c}\text { Overall (SD) } \\
\mathrm{n}=142\end{array}$ & $\begin{array}{c}\text { Males (SD) } \\
\mathrm{n}=76\end{array}$ & $\begin{array}{c}\text { Females (SD) } \\
n=66\end{array}$ & $\mathrm{M} / \mathrm{F}$ comparison \\
\hline \multirow{4}{*}{ Family } & A sense of belonging & $3.87(1.01)$ & $3.63(1.08)$ & $4.14(0.84)$ & $\mathrm{P}<0.01$ \\
\hline & A sense of one's own usefulness & $3.81(1.00)$ & $3.57(1.08)$ & $4.09(0.82)$ & $\mathrm{P}<0.01$ \\
\hline & A sense of intrinsic comfort & $4.08(1.01)$ & $3.87(1.08)$ & $4.33(0.87)$ & $\mathrm{P}<0.01$ \\
\hline & A sense of belonging & $3.47(0.91)$ & $3.32(0.91)$ & $3.65(0.89)$ & $\mathrm{P}<0.01$ \\
\hline \multirow[t]{3}{*}{ Friends at university } & A sense of one's own usefulness & $3.42(0.91)$ & $3.27(0.89)$ & $3.59(0.90)$ & $\mathrm{P}<0.01$ \\
\hline & A sense of intrinsic comfort & $3.69(0.90)$ & $3.53(0.94)$ & $3.88(0.81)$ & $\mathrm{P}<0.05$ \\
\hline & A sense of belonging & $3.67(0.92)$ & $3.70(0.88)$ & $3.62(0.97)$ & N.S. \\
\hline \multirow{2}{*}{$\begin{array}{l}\text { Friends outside } \\
\text { university }\end{array}$} & A sense of one's own usefulness & $3.62(0.92)$ & $3.67(0.88)$ & $3.56(0.96)$ & N.S. \\
\hline & A sense of intrinsic comfort & $3.86(0.92)$ & $3.83(0.87)$ & $3.89(0.98)$ & N.S. \\
\hline \multicolumn{2}{|l|}{ Psychological apathy } & $3.12(1.19)$ & $3.15(1.19)$ & $3.08(1.19)$ & N.S. \\
\hline \multicolumn{2}{|c|}{ Decreased motivation in regard to classes } & $2.97(1.36)$ & $3.14(1.40)$ & $2.78(1.28)$ & $\mathrm{P}<0.05$ \\
\hline \multicolumn{2}{|c|}{ Decreased motivation in regard to academic life } & $3.34(1.11)$ & $3.37(1.15)$ & $3.31(1.05)$ & N.S. \\
\hline \multicolumn{2}{|c|}{ Decreased motivation in regard to university } & $2.60(1.09)$ & $2.62(1.10)$ & $2.57(1.09)$ & N.S. \\
\hline \multicolumn{2}{|l|}{ Overall motivation } & $2.97(1.23)$ & $3.04(1.27)$ & $2.89(1.18)$ & N.S. \\
\hline \multicolumn{2}{|l|}{ Self-realization } & $4.61(0.64)$ & $4.55(0.70)$ & $4.68(0.56)$ & N.S. \\
\hline \multicolumn{2}{|l|}{ Career planning } & $2.99(1.10)$ & $2.95(1.16)$ & $3.09(1.03)$ & N.S. \\
\hline \multicolumn{2}{|l|}{ Career decisions } & $3.89(1.04)$ & $3.71(1.11)$ & $4.11(0.91)$ & $\mathrm{P}<0.05$ \\
\hline \multicolumn{2}{|l|}{ Overall career } & $3.84(1.15)$ & $3.74(1.20)$ & $3.96(1.08)$ & N.S. \\
\hline
\end{tabular}


decreased motivation in regard to university and decreased motivation overall, attitude in regard to self-realization, career planning, career decisions and careers overall.

- In the group who had a boyfriend/girlfriend, a significant difference was noted between males and females in regard to a sense of belonging within the family, and a sense of one's own usefulness, which is a sub-criteria to the sense of belonging $(\mathrm{P}<0.01$ in both cases). In the group without a boyfriend/girlfriend, a significant difference was noted between males and females in regard to a sense of belonging within the family, and both a sense of one's own usefulness and a sense of intrinsic comfort within the family, which are sub-criteria to the sense of belonging $(\mathrm{P}<0.01$ in both cases), and in regard to a sense of belonging among friends at university, and both a sense of one's own usefulness and a sense of intrinsic comfort within the family, which are sub-criteria to the sense of belonging ( $\mathrm{P}<0.01$ for a sense of belonging and of one's usefulness, and $\mathrm{P}<0.05$ for $\mathrm{a}$ sense of intrinsic comfort), with males scoring higher than females.

- No significant difference in scores was recorded in regard to psychological apathy characteristics, in either the group with a boyfriend/girlfriend or that without. In regard to decreased motivation, no significant difference in scores was recorded in the group who had a boyfriend/girlfriend, but in the group who did not have a boyfriend/girlfriend, a significant difference was noted between males and females $(\mathrm{P}<0.05)$ in decreased motivation in regard to classes, with males scoring higher than females.

- The group without a boyfriend/girlfriend demonstrated a significant difference in score between males and females in regard to career decisions $(\mathrm{P}<0.05)$, with females scoring higher than males.

\subsection{Relationship between Psychological Apathy, Decreased Motivation, Career Maturity and a Sense of Belonging}

Table 3 shows the results of multiple regression analysis to demonstrate how a sense of belonging affects psychological apathy, decreased motivation and career maturity.

- A multiple regression analysis was performed on the group with a boyfriend/girlfriend, using psychological apathy, decreased motivation in regard to classes, decreased motivation in regard to academic life, decreased motivation in regard to university and decreased motivation overall, attitude in regard to self-realization, career planning, career decisions and careers overall as objective variables, and a sense of belonging, a sense of one's own usefulness and a sense of intrinsic comfort in regard to family, friends at university, friends outside university and boyfriend/ girlfriend as explanatory variables. None of the indicators showed up as significant predictive indicators of psychological apathy. In males, only a sense of one's own usefulness in regard to the boyfriend/girlfriend was a significant negative predictive indicator for decreased motivation in regard to classes $(\mathrm{P}<$ 0.05). In females, only a sense of one's own usefulness in regard to friends outside university was a significant positive predictive indicator for decreased motivation in regard to academic life $(\mathrm{P}<0.01)$. In both males and females, a sense of belonging in regard to friends at university was a significant negative predictive indicator for decreased motivation in regard to university (both $\mathrm{P}<0.01$ ). In addition, a sense of one's own usefulness in regard to friends at university was a significant negative predictive indicator for decreased motivation in regard to university $(\mathrm{P}<$ 0.05 ), while a sense of belonging in regard to friends outside university was a significant negative predictive indicator for decreased motivation in regard to university $(\mathrm{P}<0.01)$. In regard to motivation overall, both a sense of belonging and a sense of one's own usefulness in regard to friends at university were significant negative predictive indicators in females (both $\mathrm{P}<0.05$ ). In females, a sense of belonging in regard to friends outside university was a significant positive predictive indicator for careers overall $(\mathrm{P}<$ $0.01)$.

- A multiple regression analysis was performed on the group without a boyfriend/girlfriend, using psycho logical apathy, decreased motivation in regard to classes, decreased motivation in regard to academic life, decreased motivation in regard to university and motivation overall, attitude in regard to self-realization, career planning, career decisions and careers overall as objective variables, and a sense of belonging, a sense of one's own usefulness and a sense of intrinsic comfort in regard to family, friends at university and friends outside university as explanatory variables. In males, almost all categories showed up as significant predictive indicators for psychological apathy, with a multiple correlation coefficient of 0.4396 ( $\mathrm{P}<0.01)$. In females, a sense of belonging and a sense of one's own usefulness in regard to friends at university were significant negative predictive indicators, with a multiple correlation coefficient of 0.4963 ( $\mathrm{P}<0.01)$. Among males, only a sense of intrinsic comfort in regard to family was a significant negative predictive indicator for decreased motivation in regard to classes $(\mathrm{P}<0.01)$. Almost all categories were significant predictive indicators among males for decreased motivation in regard to academic life, 
Table 3. Results of a multiple regression analysis on the group (a) with a boyfriend/girlfriend (by gender), showing the relationships between a sense of belonging, a sense of one's own usefulness and a sense of intrinsic comfort to psychological apathy, decreased motivation and career maturity; (b) Without a boyfriend/girlfriend (by gender), showing the relationships between a sense of belonging, a sense of one's own usefulness and a sense of intrinsic comfort to psychological apathy, decreased motivation and career maturity.

(a)

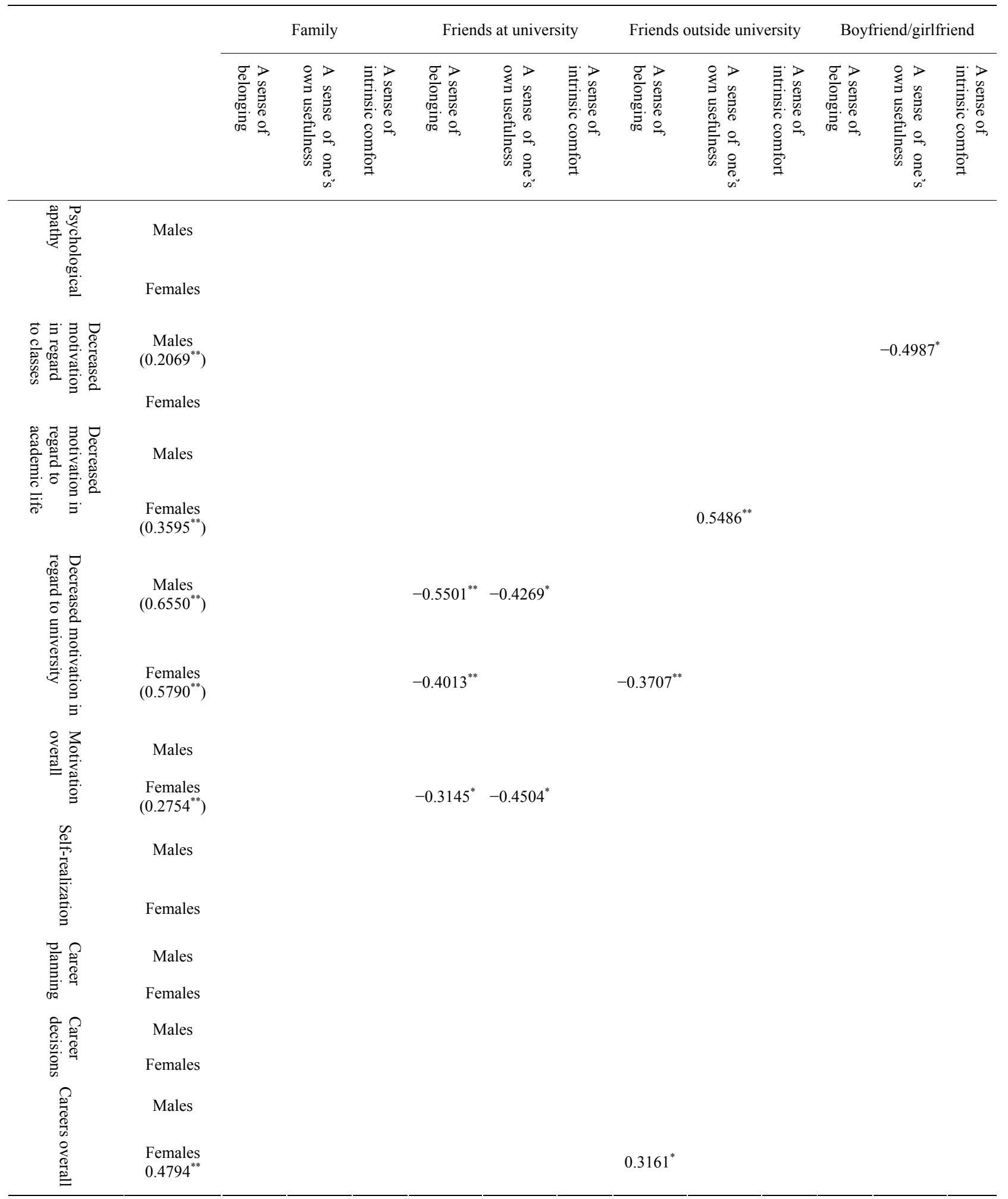

(Multiple correlation coefficient) All figures indicate standard partial regression coefficients ${ }^{* *}$ : $\mathrm{P}<0.01{ }^{*}: \mathrm{P}<0.05$. 
(b)

\begin{tabular}{|c|c|c|c|c|c|c|c|c|c|c|}
\hline & & \multicolumn{3}{|c|}{ Family } & \multicolumn{3}{|c|}{ Friends at university } & \multicolumn{3}{|c|}{ Friends outside university } \\
\hline & & 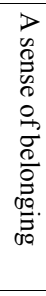 & 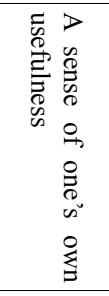 & 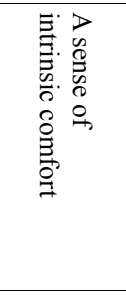 & 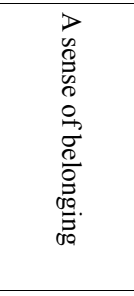 & 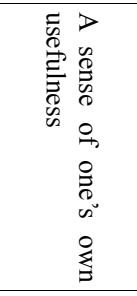 & 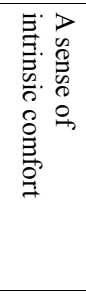 & 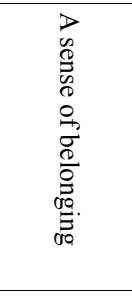 & 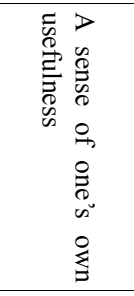 & 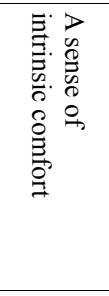 \\
\hline 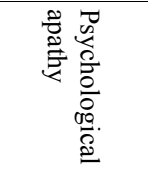 & $\begin{array}{c}\text { Males } \\
\left(0.4396^{* *}\right) \\
\text { Females } \\
\left(0.4963^{* *}\right)\end{array}$ & & $0.5079^{* *}$ & $-0.2602^{*}$ & $-0.3162^{*}$ & $\begin{array}{l}-0.3696^{*} \\
-0.5047^{* *}\end{array}$ & & $-0.3751^{* *}$ & $-0.3303^{*}$ & \\
\hline 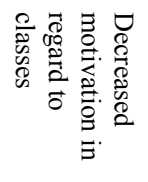 & $\begin{array}{c}\text { Males } \\
\left(0.2410^{* *}\right) \\
\text { Females }\end{array}$ & & & $-0.3860^{* *}$ & & & & & & \\
\hline 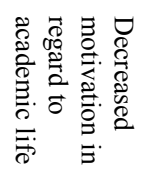 & $\begin{array}{c}\text { Males } \\
\left(0.3339^{* *}\right) \\
\text { Females }\end{array}$ & & $0.3882^{*}$ & & $-0.4298^{* *}$ & $-0.5382^{* *}$ & & $0.3067^{*}$ & & $0.2646^{*}$ \\
\hline 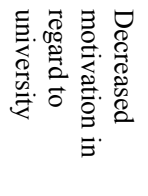 & $\begin{array}{c}\text { Males } \\
\left(0.5504^{* *}\right) \\
\text { Females } \\
\left(0.5840^{* *}\right)\end{array}$ & & & & $\begin{array}{l}-0.4786^{* *} \\
-0.3869^{* *}\end{array}$ & $-0.3968^{* *}$ & & $\begin{array}{l}-0.2274^{*} \\
-0.2664^{*}\end{array}$ & $\begin{array}{l}-0.2810^{*} \\
-0.4433^{* *}\end{array}$ & \\
\hline 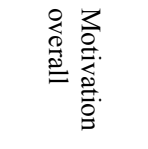 & $\begin{array}{c}\text { Males } \\
\left(0.3246^{* *}\right) \\
\text { Females }\end{array}$ & & $0.3797^{*}$ & $-0.3213^{*}$ & $-0.4257^{* *}$ & $-0.5184^{* *}$ & & & & \\
\hline 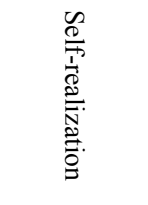 & $\begin{array}{c}\text { Males } \\
\left(0.4686^{* *}\right) \\
\text { Females } \\
\left(0.3017^{* *}\right)\end{array}$ & & & & $0.4696^{* *}$ & $0.4421^{* *}$ & & $0.3374^{*}$ & & \\
\hline 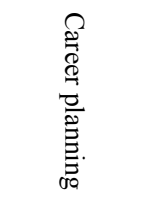 & $\begin{array}{c}\text { Males } \\
\left(0.2572^{* *}\right) \\
\text { Females }\end{array}$ & & & $0.3072^{*}$ & & & & & & \\
\hline 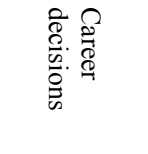 & $\begin{array}{c}\text { Males } \\
\left(0.2219^{* *}\right) \\
\text { Females }\end{array}$ & & & & $0.3252^{*}$ & & & & & \\
\hline $\begin{array}{l}0 \\
0 \\
0 \\
0 \\
0 \\
0 \\
0 \\
0 \\
0 \\
0 \\
=\end{array}$ & $\begin{array}{c}\text { Males } \\
\left(0.3082^{* *}\right) \\
\text { Females }\end{array}$ & & & & $0.3990^{* *}$ & $0.3837^{*}$ & & & & \\
\hline
\end{tabular}

(Multiple correlation coefficient) All figures indicate standard partial regression coefficients ${ }^{* *}: \mathrm{P}<0.01{ }^{*}: \mathrm{P}<0.05$. 
with a multiple correlation coefficient of 0.3339 (P < 0.01). In males, a sense of belonging and a sense of one's own usefulness among friends at university and friends outside university were significant negative predictive indicators for decreased motivation in regard to university, with a multiple correlation coefficient of $0.5504(\mathrm{P}<0.01)$. Almost the same results were noted for females, with a multiple correlation coefficient of $0.5840(\mathrm{P}<0.01)$. In regard to motivation overall, a sense of one's own usefulness and a sense of intrinsic comfort in regard to family, and a sense of belonging and a sense of one's own usefulness in regard to friends at university were significant predictive indicators, with a multiple correlation coefficient of $0.3246(\mathrm{P}<0.01)$. In males, a sense of belonging and a sense of one's own usefulness in regard to friends at university were significant positive predictive indicators for self-realization (both $\mathrm{P}<$ 0.01). In females, a sense of belonging in regard to friends outside university was a significant positive predictive indicator $(\mathrm{P}<0.05)$. Only a sense of intrinsic comfort in regard to family was a significant predictive factor in males for career planning $(\mathrm{P}<0.05)$. No significant results were found for a sense of belonging in regard to either family or friends outside university. In terms of career decisions, only a sense of belonging among friends at university was a significant predictive factor among males $(\mathrm{P}<0.05)$. In terms of careers overall, a sense of belonging and a sense of one's own usefulness in regard to friends at university were significant positive predictive factors in males, with a multiple correlation coefficient of $0.3082(\mathrm{P}<0.01)$.

\section{DISCUSSION}

Broadly speaking, females scored higher than males for a sense of belonging and a sense of one's own usefulness in regard to family and friends at university, while males scored higher for a sense of intrinsic comfort. According to Yamanaka [7], there is a gender difference in the behavior used to develop intimacy in relationships, with females prioritizing joint activity in a range of areas, while males prioritize shared activities and experiences, thus leading to the assumption that it is easy for them to feel the need for a sense of belonging among friends outside university. It is believed that these results reflect this assumption.

No significant difference was noted between males and females in terms of psychological apathy. In the future, it will be necessary to consider that student apathy is not something unique to males, but may also be experienced by females.

In regard to decreased motivation, the group without a boyfriend/girlfriend showed a significant gender differ- ence in scores for decreased motivation in regard to classes. Decreased motivation in regard to classes is said be a behavioral problem that originates with the lax lifestyle attitude of a pleasure-seeking and problem-avoiding personality [5]. The results of this study broadly lead to the conclusion that males have a stronger tendency to this than females.

In the group without a boyfriend/girlfriend, females scored significantly higher than males in regard to career maturity. It would seem that in general females are less subject to pressure in regard to careers and employment than males, but according to Kinjo [8], since females have a higher desire for employment than men, and greater anxiety about careers, they begin to think about employment at an earlier stage, taking advice from others around them and engaging in other practical activities. It is believed that the results of this study reflect this situation.

A sense of belonging in regard to friends outside university had a suppressing effect on decreased motivation in regard to university in females among the group with a boyfriend/girlfriend, and in both males and females in the group without a boyfriend/girlfriend. There were also indications that it has a suppressing effect on psychological apathy in males in the group without a boyfriend/ girlfriend. At the same time, there are indications that it may promote decreased motivation in regard to academic life in males, and that a sense of one's own usefulness in regard to friends outside university in the group with a boyfriend/girlfriend, and a sense of intrinsic comfort in regard to friends outside university in the group without a boyfriend/girlfriend, may have a promoting effect on decreased motivation in regard to academic life among males. If we take "friends outside university" to mean the relationships engaged in outside of class but within university, for example in circle or club activities, it indicates that decreased motivation in regard to university life is suppressed because of a sense of belonging at university. Being fulfilled in activities outside of class, such as circle or club activities, increases satisfaction with day-to-day life, making it harder to descend into psychological apathy. At the same time, however, it is considered that once students find a sense of belonging among friendships in circle or club activities, and feel needed and intrinsically comfortable, they tend to become more and more committed to activities outside of class, with the result that their motivation in regard to academic life decreases. Shimoyama [5], however, found a negative association between decreased motivation in regard to classes among male students and anhedonia (lack of meaning), considered the central psychological disorder behind pathological apathy, indicating that it may include some healthy aspects. For this reason, it is believed that among males without a boyfriend/girlfriend, 
the awareness of a sense of belonging in relationships with friends outside university can have a positive influence in terms of their mental health.

According to Kinjo [8], the greater the enthusiasm with which female students engage in activities outside of class (such as part time jobs and clubs), the less such students experience a lack of information and confidence in regard to careers, and it is believed that the more these students feel intrinsically comfortable in their relationships with friends outside university, and the more involved they become with activities outside of class, the more proactive they are in their behavior relating to career decisions. According to Shimoyama [5], a tendency to decreased motivation in regard to academic life among male students has a negative association with their "searching" attitude in regard to career decisions, as well as a clear positive association with "delay" and "avoidance". In this study, results showed that a sense of intrinsic comfort in regard to friends outside university has an effect on decreasing motivation in regard to academic life, thus suggesting that decision-making in regard to future career choice has been suppressed.

Furthermore, being in a romantic relationship leads to increased self-respect and a sense of day-to-day satisfaction, not only reducing depression but also leading to a sense of self-growth and self-sufficiency in the young person as a result of being able to build satisfactory romantic relationships during adolescence. As a result, achieving a sense of belonging within a relationship with a boyfriend/girlfriend is believed to be effective in suppressing psychological apathy $[9,10]$. Despite this, however long a relationship continues for, females continue to have a sense of "relationship anxiety", and to consider that they have to fit their lives around the lifestyle of their male partner, with the result that they have a stronger sense of their lifestyle becoming disrupted than males [10]. Although they have a sense of belonging in their relationship with their boyfriend/girlfriend, they constantly feel anxiety over whether or not the romantic relationship is stable, even as the relationship becomes deeper, and for that reason they invest so much energy in their partner that they become unable to keep up with other things, resulting in their lifestyles being disrupted because they are trying to hard to fit in with their partners. It is assumed that their motivation in regard to university and academic life decreases as a result. It has been shown that an awareness of "insecurity" or "worry" in regard to a relationship with a boyfriend/girlfriend has a correlation to poor mental health [11].

In this study, it was shown that the more males without a boyfriend/girlfriend believe they are needed by their families, the easier it is for them to fall into psychological apathy. It would seem that having their existence acknowledged by the family and feeling needed ought to have a positive impact on mental health, but according to research by Mouri and Sagami [12], a correlation has been shown between male students' sense that they are restricted by their fathers, and factors for psychological apathy. In other words, such results can be expected if we consider that the sense of "being needed" is underpinned by a latent sense of "being held back". The breakdown of the survey criteria used in this study do not make such classification possible, and it is thought necessary to implement a further survey in the future in consideration of this point. Regarding the criteria for this survey, the definition of "friends outside university" was taken by some subjects to mean friends in circle and club activities, and by others to mean friends at their part-time job, etc., leading to differing results, and furthermore the criteria in this study were simplified, thus leading to the conclusion that further careful consideration of criteria will be required in order to implement more accurate analysis.

This study indicates that a sense of belonging impacts the tendency to lethargy in university students in a variety of ways, and also impacts career maturity, although only partially. In particular, good relationships with friends at university were shown to have a suppressing effect on decreased motivation in regard to university. In addition, in terms of a sense of belonging in these same relationships, we saw that a sense of one's own usefulness and a sense of intrinsic comfort had completely the opposite effect. The authors did not reach any conclusions regarding background factors and mechanisms in this study, and as a result further more detailed considerations will be required in the future, but the fact that perfunctory responses to all students demonstrating a tendency to lethargy will not only not solve said tendency, but may in fact make the situation worse, should be born in mind when offering support to such students. It is believed desirable to implement support for students with a tendency to lethargy that prioritizes suppression of psychological apathy and decreased motivation in regard to university. It is increasingly considered that the age at which lethargy is expressed has been falling, and for this reason it is hoped that future surveys of children and school pupils will lead to consideration of optimized responses and support for each of these groups.

\section{CONCLUSION}

The results of this study showed that good relationships with friends at university can suppress decreased motivation in regard to university, and that a sense of belonging also has a partial impact on career maturity. The study was implemented in regard to university students, and consideration was given to the tendency to lethargy shown by students. Recently, however, absenteeism and school adaptation have become serious prob- 
lems among elementary, junior and senior high school pupils, much of which is attributed to lethargy. For this reason, it is hoped that future surveys of children and school pupils will be implemented, and such findings will lead to the development of optimized responses and support for each of these groups.

\section{REFERENCES}

[1] Uchida, C. (2010) Apathetic and withdrawing students in Japanese universities-With regard to Hikikomori and student apathy. Journal of Medical and Dental Sciences, 57, 95-108.

[2] Ishimoto, Y. (2010) The influence of a sense of Ibasho on psychological and school adjustment in adolescence and emerging adulthood. The Japanese Journal of Developmental Psychology, 21, 278-286. (in Japanese)

[3] Ishimoto, Y. (2010) Personal Ibasho and social Ibasho: From the viewpoint of its relation to mental health, sense of authenticity, and sense of self-usefulness. The Japanese Journal of Counseling Science, 43, 72-78. (in Japanese)

[4] Shimoyama, H. (1992) A study on the subclassification of moratorium of university students: In relation to the identity development. The Japanese Journal of Educational Psychology, 40, 121-129. (in Japanese)

[5] Shimoyama, H. (1995) A study on the enervation of male university students. The Japanese Journal of Educational Psychology, 43, 145-155. (in Japanese)
[6] Nihon Shinro Shido Kyokai (1999) Atarashii gakko shinro shido no hyoka. Nihon Shinro Shido Kyokai, Shinjuku-Ku. (in Japanese)

[7] Yamanaka, K. (1994) A study of early differentiation of relatedness in relationship development among college students. The Japanese Journal of Experimental Social Psychology, 34, 105-115. (in Japanese) doi:10.2130/ijesp.34.105

[8] Kinjo, H. (2008) Sex differences of college students in career decision-making self-efficacy, career indecision behaviors, and career seeking behaviors. The Japanese Society for the Study of Career Education, 27, 15-23. (in Japanese)

[9] Kamizono, Y., Kurokawa, M. and Sakata, K. (1996) The impact of falling in love: Psychological adjustment and self-concept change. Memoirs of the Faculty of Integrated Arts and Sciences, Hiroshima University. IV, Science Reports: Studies of Fundamental and Environmental Sciences, 22, 93-104. (in Japanese)

[10] Kosaka, Y. (2009) Effects of romantic relationship among university students. The Japanese Journal of Personality, 17, 144-156. (in Japanese) doi:10.2132/personality.17.144

[11] Shimizu, H. and Daibo, I. (2005) The effect of relationship-perception on mental health in romantic relationships. Japanese Journal of Interpersonal and Social Psychology, 5, 59-65. (in Japanese)

[12] Mouri, K. and Sagami, T. (2008) A research about the relation between apathy tendency in college students and their parents' attitudes. Bulletin of the Faculty of Education Ehime University, 55, 47-53. (in Japanese) 